\title{
Study of the vegetation of spring crops in the region of South Dobrudzha in 2020
}

\author{
Radko Mihaylov ${ }^{1}$, Asparuh Atanasov ${ }^{1}$, Albena Ivanova $^{3}$, Desislava Mihaylova ${ }^{2}$ \\ 1 - Technical University of Varna, Department of Mechanics and Elements of Machines, 9010, 1 Studentska Street, Varna, Bulgaria \\ 2. - Technical University of Varna, Department of Electronics, 9010, 1 Studentska Street, Varna, Bulgaria \\ 3 - Technical University of Varna, Department of Plant Growing, 9010, 1 Studentska Street, Varna, Bulgaria \\ Corresponding author contact: rmihajlowetu-varna.bg
}

\begin{abstract}
The present study observes the development of spring crops maize and sunflower typical of the Southern Dobrudzha region. A distinct methodology for remote monitoring through the use of a small remotely piloted aircraft has been developed for the purposes of the present paper and applied accordingly. Two types of video cameras were used: for the visible range of the RGB light reflected by the plants and for the NearRed reflection close to the red light. The obtained results are presented in both tabular and graphical form and inferred, finally, in the paper are some principal conclusions about the condition of the crops under consideration.
\end{abstract}

Keywords: wheat variety, infrared camera, vegetation indices, special software

\section{$1 \quad$ Introduction}

Indices based on remote sensing to quantify the state of vegetation, namely the combination of recorded reflections of visible and infrared bands, provide a unique opportunity to track the characteristics of areas where there is vegetation - biomass in a state of growth and covering areas with leaf mass. These indices serve as a basis for assessing vegetation, ( $\mathrm{Wu}, 2015)$. The relationship between the chlorophyll content of the plants and the light reflected by them allows for a more objective evaluation of the condition of the crop in terms of diseases and abnormalities. Some of the most widely used indices are: NDVI - Normalized Difference Vegetation Index, (Rouse, 1973), EVI - Enhanced Vegetation Index, (Huete, 2002), TCI - Temperature Condition Index, (Kogan, 1995), NDWI - Normalized Difference Water Index, (Gebrehiwot, 2016), VCI - Vegetation Condition Index and SPI - Standardized Precipitation Index, (Mckee, 1993). Indices based on remote sensing data are widely used mainly in the assessment of the condition of crops, as they give an accurate idea of the agricultural conditions for the observed area and facilitate the planning of the necessary activities for the needs of precision agriculture. Another type of reflective index based on infrared light is the LAI - Leaf Area Index considered by, (Asrar, 1984). It gives the relationship between the spectrum of infrared and red light reflected from wheat and soil.

An in-depth assessment of the vulnerabilities of cultivated plants caused by complex environmental and anthropogenic factors is constantly required due to climate change. Drought as a natural phenomenon seems to have many multidimensional effects on agriculture, (Singh, 2014). Various drought assessment indices have been developed from climate and satellite data and, provided on that account, are the respective algorithms for estimating the vegetation fractions in wheat for a wide range of soil reflections, (Gitelson, 2002). Assessments of cultivated crop and crop rotation are reviewed by, (David, 2014). The possibilities and disadvantages of using different ways of measuring reflected light in passive observation methods are further explored as given by (Meroni, 2009).

Despite the increased resolution of satellite monitoring, it is not accurate enough due to the fact that the size of one pixel is 5 to $10 \mathrm{~m}$. Due account, moreover, should also be taken of their dependence on weather conditions. These data are useful for monitoring globally through the world. More detailed values are obtained by observing from a lower altitude, which can be achieved with aircraft or drones. Shooting from a low height gives an accuracy of centimeters and does not depend on the cloud cover of the ground. It can be done for and at a time that is important to obtain accurate data on the condition of crops. 
The aim of the research is to compile and experiment a methodology for remote monitoring of agricultural spring crops of corn and sunflower. As a result, to collect data on the vegetation, respectively, their condition in different regions of South Dobrudzha. Create digitized maps of the reflected light from fields planted with spring crops in the near-infrared range of the sunlight reflected by the crops.

The task of the research is to capture certain sections of the corn and sunflower fields in different regions of South Dobrudzha by means of a remote-controlled aircraft equipped with RGB (Red, Green Blue) and RGN (Red, Green, NearRed) cameras. This digitized and geographically localized photographic material should be processed with specialized software products to calculate the respective vegetation indices, of which the NDVI index is the most widely used.

\section{$2 \quad$ Material and Method}

Two remote-controlled aircraft models DJI Mavic 2 and DJI Mavic Pro were used to conduct the study, which are controlled by a software application that is installed on a smartphone or tablet, (DJI GO 4. Retrieved from: https://www.dji.com/bg/downloads/djiapp/dji-go-4).

The RGB camera of the Mavic 2 drone is a model L1D-20c_10.3_5472X3648. It is equipped with a second special camera model: MAPIR Survey 3W_RGN_3.4_4000X3000. It has a promising lens and photosensor type: Sony Exmor R IMX117 12 MP (Bayer RGB) and outer GPS/GHSS unbox UBXG7020-KT. In it, the blue color channel is modified to perceive the reflected solar radiation with a wavelength $850 \mathrm{~nm}$. The technical characteristics of the photosensor of this camera are: width 4.044 $\mathrm{mm}$, height $3.033 \mathrm{~mm}$, pixel size $1.011 \mu \mathrm{m}$, main point $X 2.022 \mathrm{~mm}$, main point $Y 1.5165 \mathrm{~mm}$. Specialized software: (Mapir Calibrating Application. Retrieved from: https//www.mapir.camera/pages/calibrating-images-in-mapir-camera-control-application) and (Mapir Camera Control. Retrieved from: https//www.mapir.camera/collections/software).

The RGB camera of the Mavic Pro drone is model FC220_4.7_4000x3000. Sensor Dimensions: $6.367[\mathrm{~mm}] \times 34.775[\mathrm{~mm}]$, matrix $1 / 2.3$ “ $\mathrm{CMOS}$, with effective pixels $12.35 \mathrm{MP}$; lens with viewing angle $78,8^{0}$; focal length $20 \mathrm{~mm}$; aperture f / 2.2; image distortion less than $1.5 \%$; focal length of $0.5 \mathrm{~m}$ to infinity; ISO for photos from 100 - 1600, for video from 100 to 3200, maximum image size 4000x3000; image format *.JPEG.

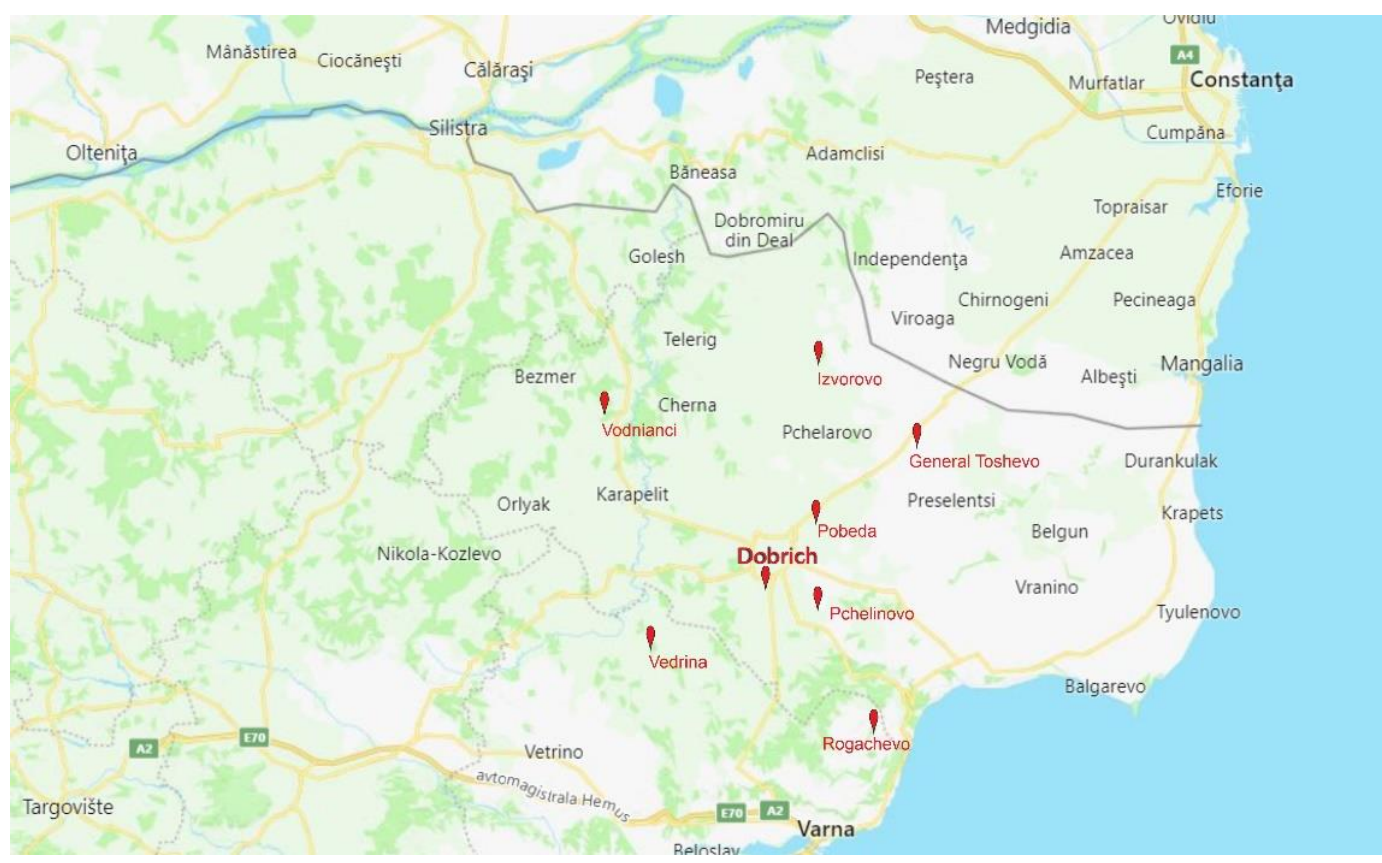

Fig. 1. Map of South Dobrudhza with marked places of interests. 
Figure 1 shows the places where the photographic material was collected. The approach in identifying it was to be relatively evenly distributed in the region of Southern Dobruja and to have massifs mainly of corn and sunflower, as in the study period (July 2020) they are still in the vegetation phase.

The methodology for surveying the areas sown with corn and sunflower includes the following activities: giving information about the location of the site: no airport nearby, long-distance pipelines, crowds, etc.; providing accurate information about the meteorological situation in the marked object for shooting. The most important parameters are: wind speed - should not be more than $8 \mathrm{~m} / \mathrm{s}$ and cloud cover should be less than $30 \%$. It is recommended that it is not low or fragmented, and that there is no possibility of precipitation and gusts of wind. Authorization should be obtained from the tenants of the agricultural land and from the aviation agency, as both drones fall into subcategory (IA) - A1. They have a take-off weight of about $900 \mathrm{~g}$, (Regulation (EU) 2019/945 of the European Commission of 12 March 2019 and Regulation (EU) 2019/947). Before the flight of the aircraft, it is set for flight mode (Table 1), which includes: altitude - about $90 \mathrm{~m}$, speed not more than $10 \mathrm{~m} / \mathrm{s}$ is determined by the wind speed as well as the requirement to overlap the photos. Maximum distance from the place of departure not more than $1.5 \mathrm{~km}$. The flight is limited, also in terms of duration, which depends on the electrical capacity of the drone batteries, its remote control and the NIR camera. The efficient and safe flight of the two drones: Mavic 2 Pro and Mavic Pro to return to the starting position is within 20 minutes with one battery charged.

The altitude of the flight affects the number of photos that the cameras take and the resolution of the images GSD (Ground Sampling Distance), (Pix4D_GSD_Calculator. Retrieved from: https//support.pix4d.com/hc/en-us/articles/202560249-TOOLS-GSD-calculator) and this is the minimum distance on the ground from which information is recorded in one pixel of the video sensor. When the flight altitude is greater, the resulting image covers a larger area, but the resolution decreases, i.e. the distance corresponding to one pixel increases. The optimal combination is at a height of $90 \mathrm{~m}$ the resolution is within $3 \mathrm{~cm}$ per pixel! The overlap of the images is also important for the subsequent processing of the photographic material. This overlap should be within $85 \%$ of the flight direction and $70 \%$ to the left and right, (Pix4Dmapper. Retrieved from: https//www.pix4d.com/download-software). These parameters are usually set in the software application used to plan the route of the drone. It is an assistance program, (Pix4DCapture. Retrieved from: https://www.pix4d.com/product/pix4dcapture) which is installed on the tablet or smartphone that controls the drone.

Table 1. Drone flight modes (missions).

\begin{tabular}{|c|c|c|c|c|c|c|}
\hline № & $\begin{array}{c}\text { Place } \\
\text { (Mission) }\end{array}$ & Camera model & $\begin{array}{l}\text { Focal length } \\
{[\mathrm{mm}]}\end{array}$ & $\begin{array}{c}\text { Flight altitude } \\
{[\mathrm{m}]}\end{array}$ & $\begin{array}{c}\text { Speed } \\
{[\mathrm{m} / \mathrm{s}]}\end{array}$ & $\begin{array}{c}\text { Resolution } \\
\text { DSM* }[\mathrm{cm} / \mathrm{in}]\end{array}$ \\
\hline 1 & Rogachevo & $\begin{array}{c}\text { MAPIR Survey } \\
\text { 3W_RGN 3.4_4000X3000 (RGN) }\end{array}$ & 3.4 & 75 & \multirow{13}{*}{5} & $5.58 / 2.20$ \\
\hline \multirow[b]{2}{*}{2} & \multirow[b]{2}{*}{ Vedrina } & L1D-20c $10.3 \quad 5472 \times 3648(\mathrm{RGB})$ & 10,3 & \multirow[b]{2}{*}{82} & & $2.72 / 1.07$ \\
\hline & & $\begin{array}{c}\text { MAPIR Survey } \\
\text { 3W_RGN_3.4_4000X3000(RGN) }\end{array}$ & 3.4 & & & $4.28 / 1.68$ \\
\hline \multirow[b]{2}{*}{3} & \multirow{2}{*}{ Vodnianci } & $\begin{array}{c}\text { FC220_4.7_4000x3000 } \\
(\mathrm{R} \text { (GB) })\end{array}$ & 4,7 & 86 & & $2.9 / 1.14$ \\
\hline & & $\begin{array}{c}\text { MAPIR Survey } \\
3 \mathrm{~W} \text { RGN } 3.44000 \times 3000(\mathrm{RGN})\end{array}$ & 3,4 & 60 & & $4.43 / 1.74$ \\
\hline \multirow[b]{2}{*}{4} & \multirow[b]{2}{*}{ Pchelino } & L1D-20c_10.3_5472X3648 (RGB) & 10.3 & \multirow[b]{2}{*}{70} & & $2.34 / 0.92$ \\
\hline & & $\begin{array}{c}\text { MAPIR Survey } \\
3 \mathrm{~W} \mathrm{RGN} 3.4 \quad 4000 \mathrm{X} 3000(\mathrm{RGN})\end{array}$ & 3,4 & & & $3.71 / 1.46$ \\
\hline 5 & $\begin{array}{l}\text { DZI Gen. } \\
\text { Toshevo }\end{array}$ & $\begin{array}{c}\text { MAPIR Survey } \\
\text { 3W_RGN 3.4_4000X3000 (RGN) }\end{array}$ & 3,4 & 54 & & $4.00 / 1.57$ \\
\hline \multirow[b]{2}{*}{6} & \multirow[b]{2}{*}{ Pobeda } & L1D-20c_10.3_5472X3648 (RGB) & 10.3 & \multirow[b]{2}{*}{60} & & $2.68 / 1.05$ \\
\hline & & $\begin{array}{c}\text { MAPIR Survey } \\
\text { 3W_RGN 3.4_4000X3000 (RGN) }\end{array}$ & 3,4 & & & $4.14 / 1.63$ \\
\hline \multirow[b]{2}{*}{7} & \multirow[b]{2}{*}{ Izvorovo } & L1D-20c $10.3 \quad 5472 \times 3648(\mathrm{RGB})$ & 10.3 & \multirow[b]{2}{*}{60} & & $1.19 / 4.7$ \\
\hline & & $\begin{array}{c}\text { MAPIR Survey } \\
\text { 3W_RGN 3.4_4000X3000 (RGN) }\end{array}$ & 3,4 & & & $4.01 / 1.58$ \\
\hline 8 & Dobrich & $\begin{array}{c}\text { MAPIR Survey } \\
3 \mathrm{~W} \text { RGN } 3.4 \quad 4000 \mathrm{X} 3000(\mathrm{RGN})\end{array}$ & 3,4 & 25 & & $1.79 / 0.70$ \\
\hline
\end{tabular}

*DSM - Digital Surface Model, 1xGSD= DSM 
The obtained maps of the reflection after the processing of the photographic material represent digitized information, the processing of which, with appropriate techniques, allows the formulation of various quantitative criteria (vegetation indices) for assessing the condition of the captured crops. In the present study, two groups of three indices were selected, which are formed by the reflections obtained from both types of cameras. The name, purpose and formula for the respective indices are given in Table 2 for those formed with RGB camera data and in Table 3 for those formed with RGN camera data. The criteria by which these two triplets of vegetation indices are selected are: the frequency of usage and the provision of objective information about the condition of the substance chlorophyll in the plants, vital for their good "health".

Table 2. Vegetation indices formed with RGB data.

\begin{tabular}{|l|c|c|}
\hline \multicolumn{1}{|c|}{ Index } & \multicolumn{1}{|c|}{ Description } & Formula \\
\hline $\begin{array}{l}\text { VIgreen - Vegetation Index } \\
\text { green }\end{array}$ & Sensitive to green vegetation. & $\frac{G R E E N-R E D}{G R E E N+R E D}$ \\
\hline $\begin{array}{l}\text { VARIgreen - Visible At- } \\
\text { mospherically Resistant In- } \\
\text { dex }\end{array}$ & Sensitive to leaf coverage. & $\frac{G R E E N-R E D}{G R E E N+R E D-B L U E}$ \\
\hline ExG - Excess Green Index & Sensitive to green vegetation. & $\begin{array}{c}E x G=2 g-r-b \\
R_{\text {Green }}\end{array}$ \\
\hline
\end{tabular}

Table 3. Vegetation indices formed with NIR data.

\begin{tabular}{|l|l|c|}
\hline \multicolumn{1}{|c|}{ Index } & \multicolumn{1}{c|}{ Description } & \multicolumn{1}{c|}{ Formula } \\
\hline $\begin{array}{l}\text { NDVI - Normalized Difference } \\
\text { Vegetation Index }\end{array}$ & Generic index used for leaf coverage and plant health & $\frac{N I R-R E D}{N I R+R E D}$ \\
\hline $\begin{array}{l}\text { GNDVI - Green Normalized Dif- } \\
\text { ference Vegetation Index }\end{array}$ & $\begin{array}{l}\text { NDVI index without red channel availability, for ar- } \\
\text { eas sensitive to chlorophyll content }\end{array}$ & $\frac{N I R-G R E E N}{N I R+G R E E N}$ \\
\hline $\begin{array}{l}\text { SIPI2 - Structure Intensive Pig- } \\
\text { ment Index 2 }\end{array}$ & $\begin{array}{l}\text { Index used in areas with high variability in canopy } \\
\text { structure (e.g. forestry) }\end{array}$ & $\frac{N I R-G R E E N}{N I R+R E D}$ \\
\hline
\end{tabular}

\section{Results and Discussion}

Table 4. Data for calculation of vegetation indices.

\begin{tabular}{|c|c|c|c|c|}
\hline \multirow{2}{*}{ Spectrum } & \multirow{2}{*}{$\begin{array}{l}\text { Wave- } \\
\text { length }\end{array}$} & RGB & Weighting coefficient's \\
\cline { 3 - 5 } & & L1D-20c $10.35472 \times 3648$ & FC220 4.7 4000x3000 & MAPIR Survey 3W_RGN_3.4_4000X3000 \\
\hline R & $660 \mathrm{~nm}$ & 0.0722 & 0.2126 & 0.2126 \\
\hline $\mathrm{G}$ & $550 \mathrm{~nm}$ & 0.2126 & 0.7152 & 0.3152 \\
\hline $\mathrm{B}$ & $470 \mathrm{~nm}$ & 0.7152 & 0.0722 & - \\
\hline NIR & $850 \mathrm{~nm}$ & - & - & 0.4722 \\
\hline
\end{tabular}

For the calculation of the vegetation indices it is important how the weight coefficients will be selected for the values of the reflection recorded on the respective channels. Information on this is given in Table 4. The values of the weights shown are selected on the basis of information from comparative previous observations.

The results for the calculated vegetation indices in numerical terms as a range of change from maximum to minimum value are recorded in Table 5 for the indices formed with data from the RGB cameras by dates, places and cultures. 
The results for the calculated vegetation indices in numerical terms as a range of change from maximum to minimum value are reported in Table 6 for the indices formed with data from the RGN camera by: dates, places and cultures.

Table 5. Vegetation indices calculated with data from RGB cameras: L1D-20c_10.3_5472X3648, FC220_4.7_4000x3000

\begin{tabular}{|c|c|c|c|c|c|c|}
\hline \multirow{3}{*}{ № } & \multirow{3}{*}{ Data } & \multirow{3}{*}{$\begin{array}{c}\text { Place } \\
\text { (Mission) }\end{array}$} & \multirow{3}{*}{$\begin{array}{c}\text { Crop/ } \\
\text { Area [ha] }\end{array}$} & \multicolumn{3}{|c|}{ Vegetation Indices } \\
\hline & & & & \multicolumn{3}{|c|}{ RGB } \\
\hline & & & & VIgreen & VARIgreen & ExG \\
\hline 1 & $\begin{array}{c}10.12 . \\
2019\end{array}$ & $\begin{array}{l}\text { Roga- } \\
\text { chevo }\end{array}$ & $\begin{array}{c}\text { Wheat } \\
26.7\end{array}$ & $0.08-(-0.11)$ & $0.12-(-0.17)$ & $0.23-(-0.03)$ \\
\hline 2 & $\begin{array}{c}09.07 . \\
2020\end{array}$ & Vedrina & $\begin{array}{l}\text { Corn } \\
4.25\end{array}$ & $0.28-(-0.09)$ & $0.41-(-0.13)$ & $0.55-(-0.02)$ \\
\hline 3 & $\begin{array}{c}16.07 . \\
2020\end{array}$ & Vodnianci & $\begin{array}{l}\text { Corn } \\
19.44\end{array}$ & $0.16-(-0.12)$ & - & $-0.01-(-0.39)$ \\
\hline 4 & $\begin{array}{c}22.07 . \\
2020 \\
\end{array}$ & Pchelino & $\begin{array}{l}\text { Corn } \\
0.08 \\
\end{array}$ & $0.20-(-0.10)$ & $0.31-(-0.16)$ & $0.44-(-0.02)$ \\
\hline 5 & $\begin{array}{c}28.07 . \\
2020\end{array}$ & Pobeda & $\begin{array}{l}\text { Corn } \\
9.6\end{array}$ & $0.15-(-0.06)$ & - & $0.11-(-0.13)$ \\
\hline 6 & $\begin{array}{c}31.07 . \\
2020 \\
\end{array}$ & Izvorovo & $\begin{array}{c}\text { Corn } \\
2.4 \\
\end{array}$ & $0.15-(-0.11)$ & - & $0.08-(-0.34)$ \\
\hline 7 & $\begin{array}{c}03.08 . \\
2020\end{array}$ & Dobrich & $\begin{array}{c}\text { Vineyard } \\
0.415\end{array}$ & $0.04-(-0.04)$ & $0.09-(-0.08)$ & $0.06-(-0.06)$ \\
\hline
\end{tabular}

Table 6. Vegetation indices calculated with RGN camera data. MAPIR Survey 3W RGN 3.4 4000X3000

\begin{tabular}{|c|c|c|c|c|c|c|}
\hline \multirow{3}{*}{ № } & \multirow{3}{*}{ Data } & \multirow{3}{*}{ Place } & \multirow{3}{*}{$\begin{array}{c}\text { Culture/ } \\
\text { Area }\end{array}$} & \multicolumn{3}{|c|}{ Vegetation Indices } \\
\hline & & & & \multicolumn{3}{|c|}{ RGN } \\
\hline & & & & NDVI & GNDVI & SIPI2 \\
\hline 1 & $\begin{array}{c}10.12 . \\
2019 \\
\end{array}$ & Rogachevo & $\begin{array}{l}\text { Wheat } \\
25.83\end{array}$ & $0.26-(-0.09)$ & $0.35-(-0.13)$ & $0.31-0.11$ \\
\hline 2 & \multirow{2}{*}{$\begin{array}{c}09.07 . \\
2020\end{array}$} & \multirow{2}{*}{ Vedrina } & $\begin{array}{c}\text { Corn } \\
0\end{array}$ & $0.84-0.81$ & $0.94-1.03$ & $1.06-1.03$ \\
\hline $2^{\prime}$ & & & $\begin{array}{c}\text { Sunflower } \\
2.93\end{array}$ & $0.83-0.8$ & $0.88-0.83$ & $1.04-1.02$ \\
\hline 3 & $\begin{array}{c}16.07 . \\
2020\end{array}$ & Vodnianci & $\begin{array}{c}\text { Corn } \\
9.8\end{array}$ & $0.56-0.46$ & $0.78-0.55$ & $1.26-1.1$ \\
\hline 4 & $\begin{array}{c}23.07 . \\
2020\end{array}$ & Pchelino & $\begin{array}{l}\text { Corn } \\
11.98 \\
\end{array}$ & $0.82-0.65$ & $0.92-0.72$ & $1.09-1.03$ \\
\hline 5 & \multirow{2}{*}{$\begin{array}{c}28.07 . \\
2020\end{array}$} & \multirow{2}{*}{$\begin{array}{c}\text { DZI Gen. } \\
\text { Toshevo }\end{array}$} & $\begin{array}{l}\text { Corn } \\
7.25 \\
\end{array}$ & $0.78-0.56$ & $0.9-0.62$ & $1.1-1.03$ \\
\hline 5 & & & $\begin{array}{c}\text { Sunflower } \\
6.7\end{array}$ & $0.27-(-0.19)$ & $0.33-(-0.22)$ & $0.33-(-0.20)$ \\
\hline 6 & $\begin{array}{c}30.07 . \\
2020\end{array}$ & Pobeda & $\begin{array}{c}\text { Corn } \\
8.5 \\
\end{array}$ & $0.74-0.43$ & $0.86-0.54$ & $1.19-0.03$ \\
\hline 7 & $\begin{array}{c}31.07 . \\
2020\end{array}$ & Izvorovo & $\begin{array}{l}\text { Corn } \\
8.25\end{array}$ & $0.6-0.3$ & $0.78-0.37$ & $1.29-0.99$ \\
\hline 8 & $\begin{array}{c}06.08 . \\
2020 \\
\end{array}$ & Dobrich & $\begin{array}{c}\text { Vineyard } \\
0.1877\end{array}$ & $0.53-(-0.39)$ & $0.73-(-0.39)$ & $0.55-(-0.36)$ \\
\hline
\end{tabular}

Figures 2, 3 and 4 show the data from Tables 5 and 6 in graphical form. Figure 2 provides information on the limits of variation of the three indices formed by the reflection of visible light for all three observed crops, and the next two only for the maize crop, as the largest number of observations were made for it. 


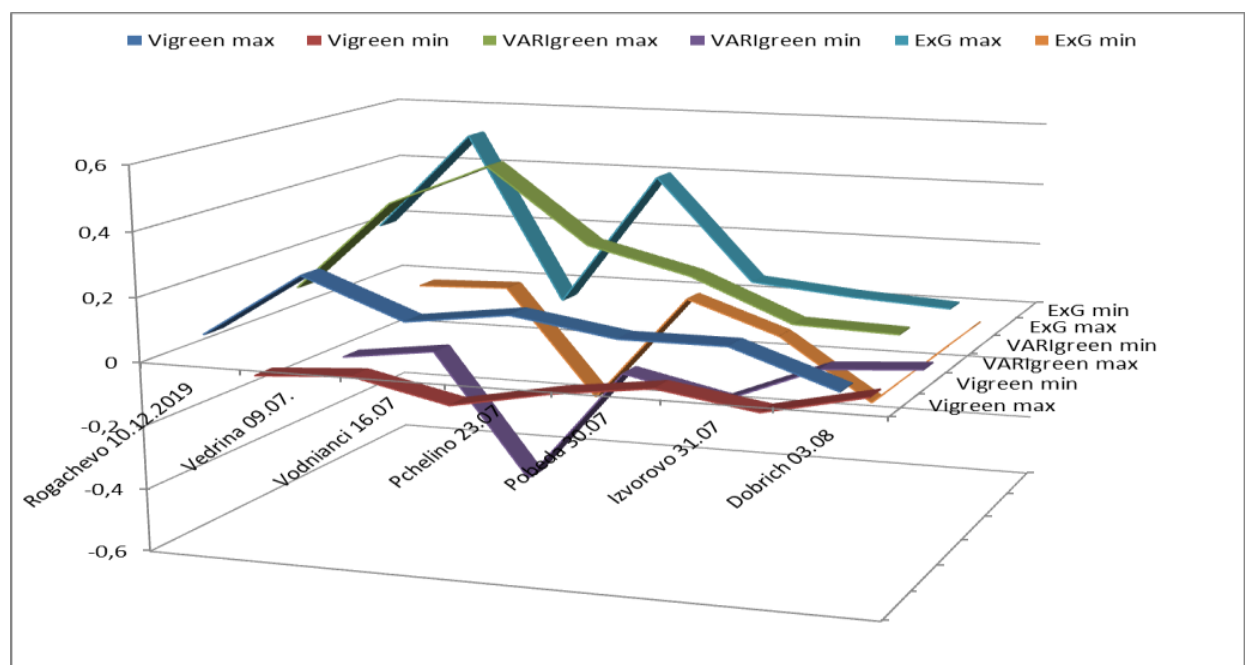

Fig. 2. Graph for the values of RGB vegetation indices by places for wheat, corn and vines.

The data for the RGB formed indices (Table 5 and Fig. 2 and 4) shows good condition of the observed crops.

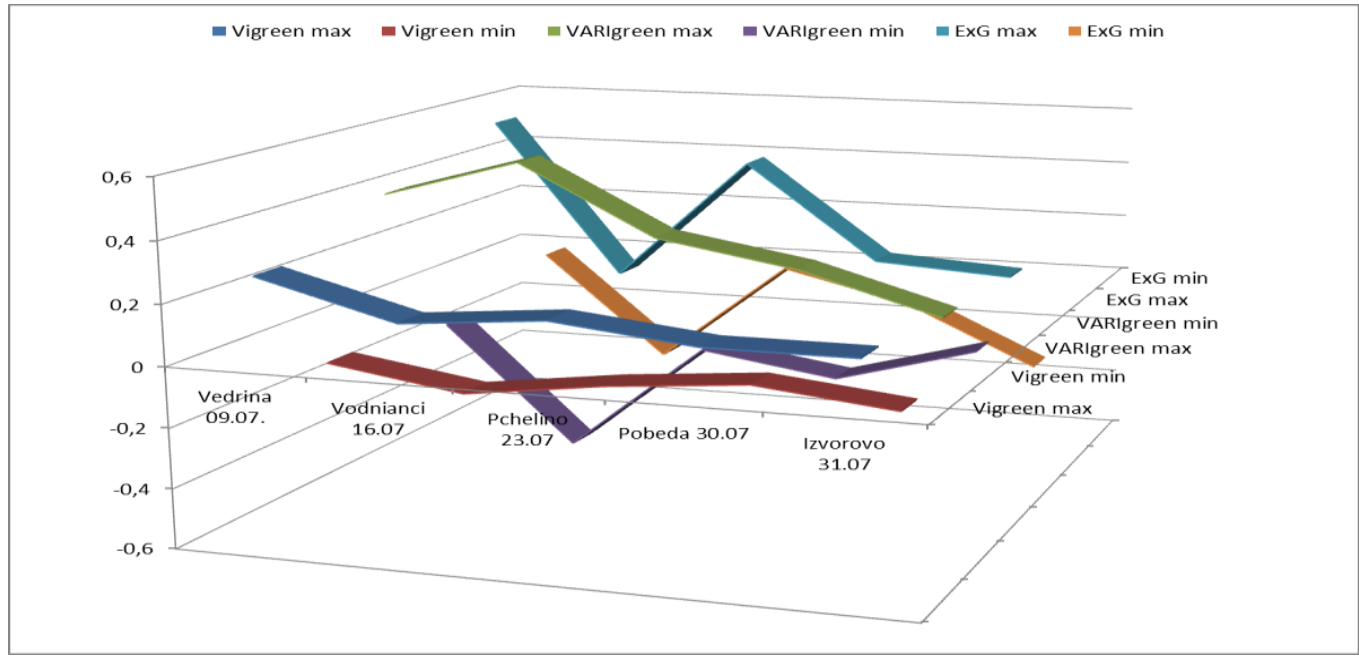

Fig. 3. Graph for the values of RGN vegetation indices by places for maize.

The most frequently used vegetation index NDVI for the observed maize (Table 6 and Fig. 3 ) is in the range from 0.6 (village of Izvorovo) to 0.84 (village of Vedrina), which shows that these crops are in very good "health", i.e. in very good condition in terms of vegetation and no presence of diseases. With the lowest possible limit 0.3 being registered in the village of Izvorovo, which is ascribed to the sharp changes in the meteorological conditions during the process of observation, namely- clouding, which strongly affected the parameters of the reflected light. 


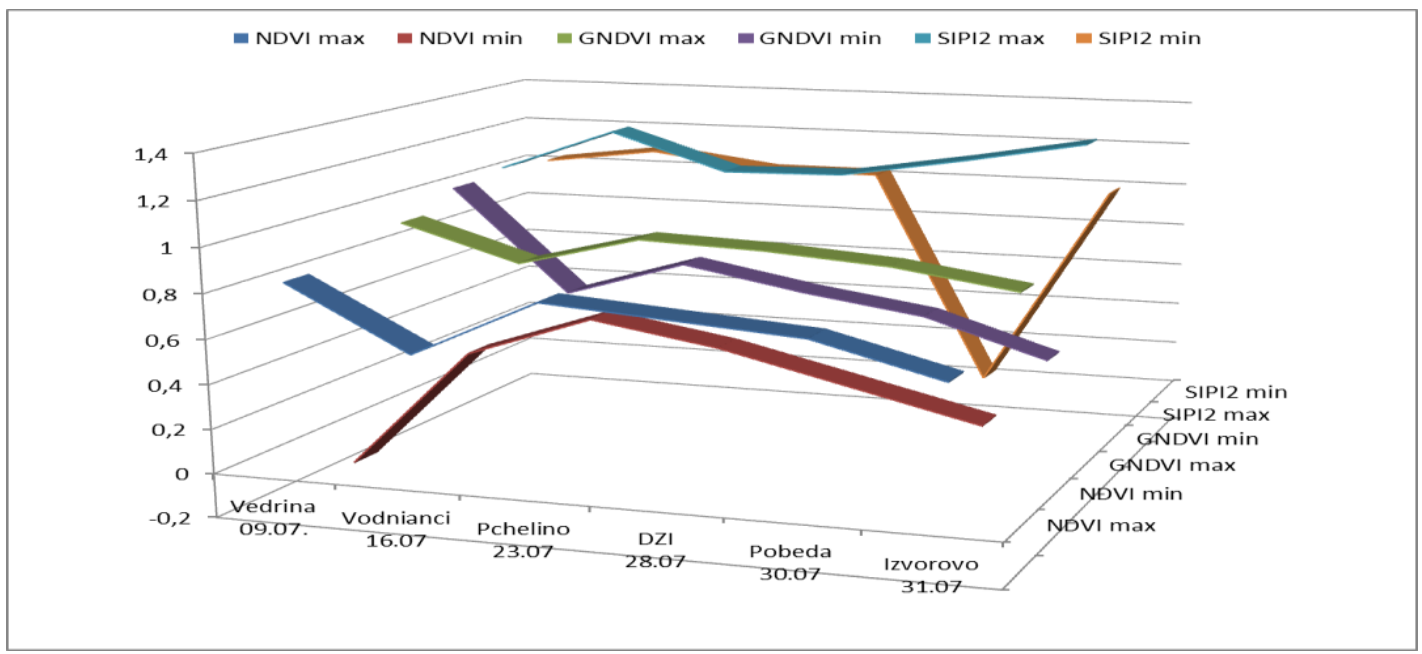

Fig. 4. Graph for the values of RGB vegetation indices by places for maize.

\section{Conclusions}

The developed and experimented methodology for remote sensing for spring crops: corn and sunflower during their growing season in July 2020, yields positive qualitative and quantitative results for their condition, given that they are developed plants with stem height over $1.7 \mathrm{~m}$. inferred, therefore, in the light of the foregoing, is that aerial observation at a relatively low altitude between 50 and 90 meters is the only way to obtain reliable, timely quantitative information on medium and small size flights, such as up to 400 decares.

The general conclusion from the research is that this is a modern, promising and reliable method for monitoring medium-sized plant-sown areas, which does not, in itself, require large investments, but is capable of providing very accurate, useful, and timely information about crop development.

\section{Acknowledgment's}

The paper proposed herein is funded by a budget subsidy from the Technical University of Varna under project NP9/2020.

\section{References}

Asrar, G., Fuchs, M., Kanemasu, E. T., \& Hatfield, J. L. (1984). Estimating absorbed photosynthetic radiation and leaf area index from spectral reflectance in wheat. Agronomy Journal, 76, 300- 306. https://doi.org/10.2134/agronj1984.00021962007600020029x

David, G., Burke, J., \& Dawes, J. (2014). A novice experiment with satellite-based classification of agricultural crops and bmps, 11

COMMISSION DELEGATED REGULATION (EU) 2019/945 of 12 March 2019 "on unmanned aerial vehicles and unmanned aerial vehicle operators from third countries" Official Journal of the European Union L152 / 1 of 11.06.2019

Gitelson, A., Stark, R., Grits, U., Rundquist, D., Kaufman, Y., \& Derry, D. (2002). Vegetation and soil lines in visible spectral space: a concept and technique for remote estimation of vegetation fraction. https://doi.org/10.1080/01431160110107806

Gebrehiwot, T., Van der Veen, A., \& Maathuis, B. (2016). Governing agricultural drought: Monitoring using the vegetation condition index. Ethiop. J. Environ. Stud. Manag., 9, 354. https://doi.org/10.4314/ejesm.v9i3.9 
Huete, A., Didan, K., Miura, T., Rodriguez, E., Gao, X., \& Ferreira, L. (2002). Overview of the radiometric and biophysical performance of the MODIS vegetation indices. Remote Sensing of Environment. 83195-213. https://doi.org/10.1016/S0034-4257(02)00096-2

Kogan, F., (1995). Droughts of the late 1980s in the United States as derived from NOAA polar-orbiting satellite data. Bull. Am. Meteorol. Soc., 76, 655-668. https://doi.org/10.1175/1520-0477(1995)076<0655:DOTLIT>2.0.CO;2

Mckee, T., Doesken, N., \& Kleist, J. (1993). The relationship of drought frequency and duration to time scales. In Proceedings of the 8th Conference on Applied Climatology, Anaheim, CA, USA, 17-22 January 1993; American Meteorological Society: Boston, MA, USA,; pp. 179-184.

Meroni, M., Rossini, M., Guanter, L., Alonso, L., Rascher, U., Colombo, R. \& Moreno, J., (2009). Remote sensing of solar-induced chlorophyll fluorescence: review of methods and applications. Remote Sensing Environ., 113, 2037-2051. https://doi.org/10.1016/j.rse.2009.05.003

Rouse, Jr., Haas, H., Schell, A., \& Deering, W. (1973). Monitoring vegetation systems in the Great Plains with ERTS, Third ERTS Symposium. NASA, 1, 309-317

Running, S. W., Nemani, R. R., Heinsch, F. A., Zhao, M. S., Reeves, M. \& Hashimoto, H. (2004). A continuous satellite-derived measure of global terrestrial primary production. Bioscience, 54, 547-560. https://doi.org/10.1641/0006-3568(2004)054[0547:ACSMOG]2.0.CO;2

Singh, P., Bantilan, C., Byjesh, K. (2014). Vulnerability and policy relevance to drought in the semi-arid tropics of Asia-A retrospective analysis. Weather Clim. Extrem., 3, 54-61. https://doi.org/10.1016/j.wace.2014.02.002

Wu, D., Qu, J., \& Hao, X. (2015). Agricultural drought monitoring using MODIS-based drought indices over the USA Corn Belt. Int. J. Remote Sens., 36, 5403-5425. https://doi.org/10.1080/01431161.2015.1093190

\section{Online sources}

Cadastral-administrative information system. Retrieved from URL https://kais.cadastre.bg/bg/Map

DJI GO 4. Retrieved from: https://www.dji.com/bg/downloads/djiapp/dji-go-4

Mapir Calibrating Application. Retrieved from: https//www.mapir.camera/pages/calibrating-images-in-mapircamera-control-application

Mapir Camera Control. Retrieved from: https//www.mapir.camera/collections/software)

Pix4DCapture. Retrieved from: https://www.pix4d.com/product/pix4dcapture

Pix4D_GSD_Calculator. Retrieved from: https//support.pix4d.com/hc/en-us/articles/202560249-TOOLS-GSDcalculator

Pix4Dmapper. Retrieved from: https//www.pix4d.com/download-software 